\title{
A Genomic Alternative to Identify Medullary Thyroid Cancer Preoperatively in Thyroid Nodules with Indeterminate Cytology
}

\author{
Richard T. Kloos, ${ }^{1}$ Robert J. Monroe, ${ }^{2}$ S. Thomas Traweek, ${ }^{3}$ Richard B. Lanman, ${ }^{1 \dagger}$ and Giulia C. Kennedy
}

Background: The use of calcitonin screening for the rare medullary thyroid cancer (MTC) is controversial due to questions of efficacy, accuracy, and cost-effectiveness. This study reports the results of a large prospective validation using a machine-trained algorithm (MTC Classifier) to preoperatively identify MTC in fine-needle aspiration biopsies in lieu of calcitonin measurements.

Methods: Cytology analysis on a prospective consecutive series of 50,430 thyroid nodule biopsies yielded a total of 7815 indeterminate (Bethesda categories III/IV) cases, which were tested with the MTC classifier. A prospective, consecutively submitted series of 2673 Bethesda III-VI cases with cytology determined locally was also evaluated. RNA was isolated and tested for the MTC Classifier using microarrays.

Results: Forty-three cases were positive by the MTC Classifier among 10,488 tested nodules $(0.4 \%)$, consistent with the low prevalence of MTC. Of these, all but one was histologically or biochemically confirmed as MTC, yielding a positive predictive value (PPV) of $98 \%$. Of the positive cases, only 19 (44\%) had been specifically suspected of MTC by cytology, highlighting the limitations of light microscopy to detect this disease. Three surgically confirmed MTC cases that were detected by the MTC Classifier had low basal serum calcitonin values, indicating these would have been missed by traditional calcitonin screening methods. A pooled analysis of three independent validation sets demonstrates high test sensitivity (97.9\%), specificity (99.8\%), PPV $(97.9 \%)$, and negative predictive value $(99.8 \%)$.

Conclusions: A clinical paradigm is proposed, whereby cytologically indeterminate thyroid nodules being tested for common malignancies using gene expression can be simultaneously tested for MTC using the same genomic assay at no added cost.

\section{Introduction}

$\mathbf{M}$ EDULLARY THYROID CANCER (MTC) accounts for only $2.2 \%$ of thyroid cancers, but is responsible for up to $13.5 \%$ of its mortality $(1,2)$. Almost $50 \%$ of the more common sporadic MTC (sMTC) cases present at stage III or IV disease, with no evidence of increased survival in recent decades $(3,4)$. Together, these findings underscore the limitations of the current diagnostic paradigm and the need for earlier and more accurate diagnosis of sMTC. However, given its rarity, at what point in the clinical diagnostic workflow should testing for MTC be performed? How should clinical efficiency be optimized with the need for high sensitivity to identify cancer and specificity to avoid false positive results?
Challenges in interpreting cytology result in one-half of MTC cases being missed $(5,6)$. A specific diagnosis of MTC is critical to planning the optimal surgery, which is more extensive than for thyroid nodules in which MTC is not specified.

Unfortunately, many sMTC patients undergo suboptimal preoperative evaluations and initial surgical interventions (68 ), resulting in additional "completion" surgeries and/or compromised patient outcomes. Appropriate surgery results in fewer local reoperations and more frequent biochemical cure (9). In addition, when MTC is not suspected, more than one-quarter of patients with cytologically indeterminate fineneedle aspiration biopsies (FNABs) do not undergo surgical resection in the short term (10), an approach that would delay

\footnotetext{
${ }^{1}$ Department of Medical Affairs; ${ }^{2}$ CLIA; ${ }^{4}$ Department of Research and Development, Veracyte, Inc., South San Francisco, California. ${ }^{3}$ Thyroid Cytopathology Partners, Austin, Texas.

Current address: Department of Medical Affairs, Guardant Health, Inc., Redwood City, California.

(c) Richard T. Kloos et al. 2016; Published by Mary Ann Liebert, Inc. This Open Access article is distributed under the terms of the Creative Commons Attribution Noncommercial License (http://creativecommons.org/licenses/by-nc/4.0/) which permits any noncommercial use, distribution, and reproduction in any medium, provided the original author(s) and the source are credited.
} 
the diagnosis and treatment of MTCs missed by cytology (6). Conversely, a false diagnosis of MTC can lead to an overly aggressive surgery $(6,11-13)$.

Many approaches for improving the preoperative diagnosis of MTC have been suggested, and some implemented, with varying degrees of success. A negative result on a large mutation panel does not adequately exclude sporadic MTC $(14,15)$. As medullary thyroid tumors often overproduce calcitonin, screening for its production, either by immunohistochemistry, or by measurement in the serum, has been a focus of diagnostic efforts. The presence of MTC across all six Bethesda cytopathology categories $(6,12,16)$ requires that any testing paradigm take into account this distribution when testing for MTC, and must be considered against a backdrop of its rarity. Efforts to improve the diagnostic FNAB pathway could include making a cell block on every FNAB and performing immunohistochemical staining for calcitonin on those that are not cytologically benign. This approach is often challenged by insufficient residual cells for production of the cell block, as well as cost given the rarity of MTC. In addition, sMTC seem to be less frequently immunoreactive for calcitonin $(74-79 \%)$ than familial cases are $(100 \%)(17)$. Serum calcitonin screening is limited by lack of agreement on the calcitonin threshold to suspect MTC, no prospective randomized studies demonstrating improved patient outcome by calcitonin screening, and questions about cost-effectiveness not only given the rarity of MTC but also because of the downstream effects of false positive results (18-22). While serum calcitonin screening is accepted in some countries such as Germany and Italy, it is not uniformly accepted in the United States and elsewhere, resulting partly from its high false positive rate (60-90\%) and low positive predictive value (PPV) of $10-40 \%$ (23). Thus, serum calcitonin screening thresholds with high sensitivity may drive unnecessary MTC-related testing and surgery in patients who do not have MTC.

It was reasoned that if there were a paradigm for testing FNAs from indeterminate nodules, an additional classifier could be incorporated to test for MTC without incurring the expense and effort of a separate test. Recently, machine learning was used to develop an algorithm that uses mRNA gene expression data from thyroid FNAB samples to reclassify cytologically indeterminate nodules as benign or suspicious, with high sensitivity and negative predictive value (NPV). This classification algorithm (Afirma ${ }^{\circledR}$ Gene Expression Classifier [GEC]) uses 142 genes to separate benign and suspicious nodules, but the presence of nearly 3000 genes on the microarray allows future tests to be added by developing algorithms on different gene sets for different diagnostic purposes. This approach was used to develop a classifier for MTC $(24,25)$, and as all genes are measured with one assay on one microarray, the MTC result is generated concurrently with the GEC result at no added cost. The MTC portion of the classifier was trained by analyzing expression data on 22 known MTC cases from 220 surgical tissues, confirmed by histopathology. Using machine learning and feature selection on 283,927 gene transcripts measured in training, a group of five genes was selected (CALCA, CEACAM5, SCG3, SCN9A, and SYT4), which together have high accuracy for detecting MTC (Table 1) (24,25).

After the MTC Classifier was trained and locked, two independent FNAB sample sets with a combined total of 489 samples were tested to establish clinical validation (Tables 2 and 3) (24,25). Those studies showed high specificity and high NPV of the MTC Classifier. Here, the MTC Classifier is tested on 10,488 thyroid nodule FNAB samples referred for GEC testing from a large prospective clinical series of 53,103 consecutively received thyroid nodule FNABs, the largest cohort tested to date (Fig. 1 and Table 4). A pooled analysis combining all three studies demonstrates exceptionally high diagnostic accuracy (Table 5).

\section{Materials and Methods}

\section{The Bethesda System for Reporting Thyroid Cytopathology}

The six categories in the Bethesda System for Reporting Thyroid Cytopathology are: Bethesda I (non-diagnostic or unsatisfactory); Bethesda II (benign); Bethesda III (atypia or follicular lesion of undetermined significance [AUS/FLUS]); Bethesda IV (suspicious for follicular or Hürthle cell neoplasm [SFN/SHCN]), Bethesda V (suspicious for malignancy), and Bethesda VI (malignant) (26).

\section{Experimental design}

This protocol was reviewed and granted Institutional Review Board exempt status (Liberty IRB, DeLand, FL). Patients were prospectively derived from two diagnostic pathways (Fig. 1). The first was centralized cytological evaluation of thyroid nodule FNABs with routine GEC testing for Bethesda III/IV nodules, and testing for Bethesda V/VI nodules only upon physician's request. This process accrued 50,430 thyroid nodules between December 1, 2010, and June 26, 2013, and included 5883 Bethesda III and 1932 Bethesda IV nodules. Second, an additional 2673 GEC samples, mostly from Bethesda III/IV and a smaller fraction from Bethesda

Table 1. Training Set

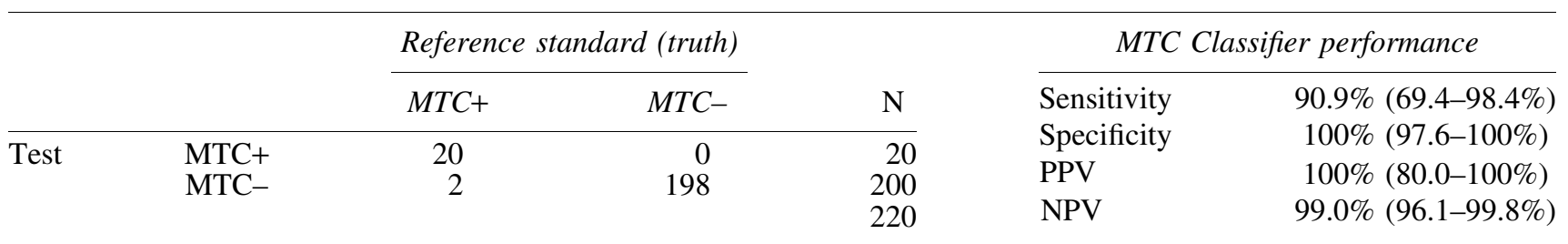

The Chudova et al. (25) supplement briefly describes the MTC Classifier training methodology.

Multicenter study utilizing 220 banked surgical tissue samples with local histopathology truth. Pathologists masked to molecular results. Leaveone-out cross-validation. Previously unpublished data. The Alexander et al. (24) supplement lists the genes included in the MTC Classifier.

MTC, medullary thyroid cancer; PPV, positive predictive value; NPV, negative predictive value. 
Table 2. Independent Validation Set 1 from Chudova et al. (25)

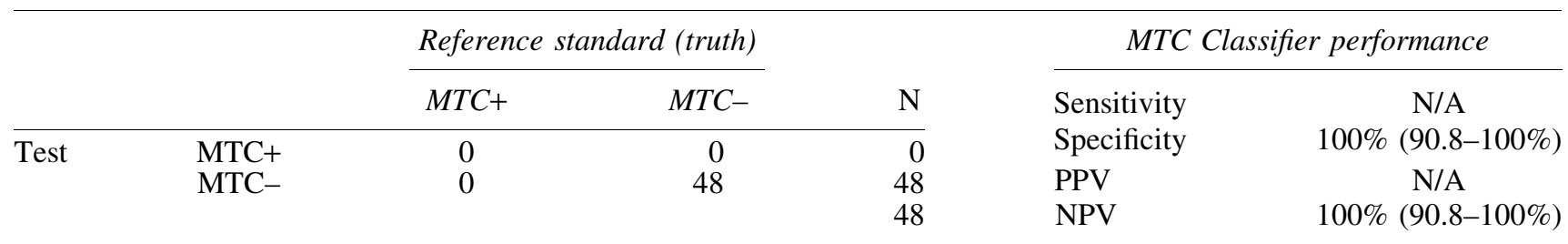

Prospective, multicenter fine-needle aspiration biopsy (FNAB) samples. Local cytopathology assigned Bethesda I-VI. Truth based on expert by central histopathology expert(s) or local pathologist. Pathologists masked to molecular results. Previously unpublished data.

V/VI nodules, were submitted mainly from academic centers where cytology was performed locally. All samples from either pathway were prospectively and consecutively tested with the MTC Classifier. The testing was conducted in a blinded manner, with the laboratory personnel unaware of clinical patient information and final histopathologic diagnosis.

Clinical details were collected on all patients who were tested with the GEC, and who either had cytological results suspicious for MTC or diagnostic for MTC, or who tested positive with the MTC Classifier. All clinical information was obtained in compliance with the Health Insurance Portability and Accountability Act from treating physicians by Veracyte Medical Directors under the Clinical Laboratory Improvement Amendments mandate of test result quality assurance. Three patients were found to have Bethesda V/VI cytology with suspicion for MTC, but they did not undergo GEC testing and were excluded from further analysis.

As Bethesda V and VI FNAB samples are not automatically reflexed to GEC testing, the prevalence of positive MTC Classifier results in these two cytopathology categories were examined in a consecutive series of de-identified FNAB samples with Bethesda V $(n=104)$ and Bethesda VI $(n=111)$ cytopathology (Figs. 1 and 2).

\section{Reference standards}

Biochemical and rearranged during transfection (RET) proto-oncogene mutation analyses were performed according to local clinical practice. Calcitonin was most often measured with the Siemens (DPC) Immulite 2000 assay with a reported reference range of approximately $<2-5 \mathrm{ng} / \mathrm{L}$ for women and $<2-8.4 \mathrm{ng} / \mathrm{L}$ for men. Relevant MTC testing (including measurement of serum calcitonin) was routinely recommended by (a) Veracyte medical director(s) when the MTC Classifier detected the MTC signature. Local surgical pathology served as the gold standard for confirmation of MTC when it was obtained. When surgical pathology was not obtained (three cases), patients with serum basal calcitonin levels $>80 \mathrm{ng} / \mathrm{L}$ were considered to have MTC, given the high PPV at this cutoff (27-29). This approach allowed an outcome to be assigned to patients with positive MTC Classifier results. However, an outcome was not assigned to the overwhelming majority of patients with negative MTC Classifier results. Thus, sensitivity could not be calculated on this cohort. Elsewhere, MTC Classifier sensitivity was reported on MTC tissue samples with histologically confirmed truth as $96.3 \%$ [confidence interval (CI) 81.0-99.9\%] (30). The upper reference range of serum calcitonin in adult women and men is approximately $5.2 \mathrm{ng} / \mathrm{L}$ and $11.7 \mathrm{ng} / \mathrm{L}$, respectively (31).

\section{Statistical analysis}

The two-sided CI of a proportion was calculated with continuity correction (32).

\section{Results \\ Bethesda III cytopathology}

Among 5883 consecutive prospective thyroid nodules with Bethesda III cytopathology, the MTC Classifier identified 11 cases $(0.19 \%$; Fig. 2 ) as MTC. MTC was confirmed histologically in all cases, except for a 54-year-old female whose surgical histology demonstrated a $1.4 \mathrm{~cm}$ intrathyroidal paraganglioma arising within an intrathyroidal parathyroid gland. In another case, a 62-year-old female with a baseline serum calcitonin of $122 \mathrm{ng} / \mathrm{L}$ was initially considered to have Hürthle cell carcinoma that was reclassified as an oncocytic variant of MTC with a mixed follicular component upon independent expert histopathology review and ultimately considered an MTC Classifier true positive. Of the 10 histologically confirmed MTC cases, nine had preoperative serum calcitonin results $(M=2018 \mathrm{ng} / \mathrm{L}$; range $122-10,702 \mathrm{ng} / \mathrm{L}$; Fig. 3).

Table 3. Independent Validation Set 2 from Alexander et al. (24)

\begin{tabular}{|c|c|c|c|c|c|c|}
\hline & & \multicolumn{2}{|c|}{ Reference standard (truth) } & \multirow[b]{2}{*}{$\mathrm{N}$} & \multicolumn{2}{|c|}{ MTC Classifier performance } \\
\hline & & $M T C+$ & $M T C-$ & & Sensitivity & $100 \%(39.6-100 \%)$ \\
\hline \multirow[t]{3}{*}{ Test } & MTC+ & 4 & 0 & $\overline{4}$ & Specificity & $100 \%(98.9-100 \%)$ \\
\hline & MTC- & 0 & 437 & 437 & PPV & $100 \%(39.6-100 \%)$ \\
\hline & & & & 441 & NPV & $100 \%(98.9-100 \%)$ \\
\hline
\end{tabular}

Prospective, consecutive, multicenter FNAB samples. Local cytopathology assigned Bethesda III-VI by expert cytopathology review of local reports, truth based on expert central histopathology panel review. Pathologists masked to molecular results. Two of the four histologically confirmed MTC cases were excluded from the final analysis in Alexander et al. due to pre-specified exclusions (one for deviation in storage conditions, and one because a contralateral nodule was used for Classifier training) but are included here. 


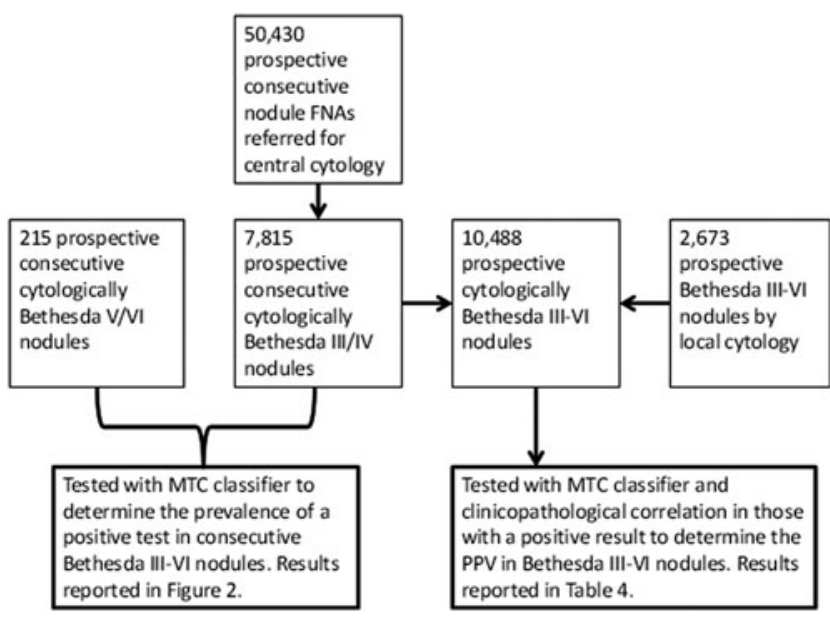

FIG. 1. Study design flow diagram.

In one Bethesda III case, the cytological description specifically noted that MTC could not be excluded. The GEC result was suspicious, but the MTC Classifier did not detect MTC. Final surgical pathology demonstrated papillary thyroid carcinoma (PTC) surrounded by Hashimoto's thyroiditis.

\section{Bethesda IV cytopathology}

Among the 1932 consecutive prospective thyroid nodules with Bethesda IV cytology, the MTC Classifier identified nine cases $(0.47 \%$; Fig. 2$)$ as MTC. An additional six cases were prospectively identified by the MTC Classifier from the 2673 specimens whose cytopathology was read locally. Of these 15 patients, one patient refused surgery and had no laboratory testing, and one patient demonstrated sex discordance from that of the reference nodule. These two cases are included in MTC signature prevalence calculations, but are excluded from PPV calculations, given the uncertainty in final surgical pathology. The remaining 13 cases were all confirmed to be MTC with either surgical pathology (12 cases) or calcitonin (one case). Of the 12 patients with surgically confirmed MTC, 11 had preoperative serum calcitonin values $(M=1949 \mathrm{ng} / \mathrm{L}$; range $8-6866 \mathrm{ng} / \mathrm{L}$; Fig. 3). The one patient considered to have MTC without surgical pathology had marked elevations of basal serum calcitonin $(11,272 \mathrm{ng} / \mathrm{L})$ and CEA $(745.7 \mu \mathrm{g} / \mathrm{L})$.

\section{Bethesda V cytopathology}

Among 104 consecutive prospective and blinded thyroid nodules with Bethesda V cytology, the MTC Classifier was positive in one case $(0.96 \%$; Fig. 2). In clinical practice, Bethesda V cases are not routinely tested with the GEC or MTC Classifier. Among Bethesda V cases whose physician requested MTC Classifier testing, 13 cases were positive, and all were confirmed to be MTC with surgical pathology (12 cases) or calcitonin (a 57-year-old female with a serum calcitonin of $88 \mathrm{ng} / \mathrm{L}$ without thyroid surgery). In 11/13 cases, the cytology description included suspicion for MTC, while no cytological suspicion was present in two cases. In one of these two cases, a 45-year-old female had a preoperative serum calcitonin level of $5 \mathrm{ng} / \mathrm{L}$, and the biopsied nodule was $1 \mathrm{~cm}$ MTC on surgical pathology. In the second case, a 36year-old female with a preoperative serum calcitonin level of $34 \mathrm{ng} / \mathrm{L}$ had a $7 \mathrm{~mm}$ MTC on surgical pathology of the biopsied nodule. All 12 patients with surgically confirmed MTC had preoperative serum calcitonin values obtained ( $M=1921$ ng/L; range 5-6912 ng/L; Fig. 3).

In five Bethesda $\mathrm{V}$ cases, the cytological description specifically noted suspicion for MTC, but the mRNA signature did not suggest MTC. None demonstrated MTC on surgical pathology. Surgical pathology demonstrated PTC in one, follicular adenomas in two, and adenomatous nodules in two. Hürthle cell changes were reported in three of the cases. Preoperative serum calcitonin levels, measured in four cases, ranged from $<2$ to $22 \mathrm{ng} / \mathrm{L}$.

\section{Bethesda VI cytopathology}

Among 111 consecutive prospective thyroid nodules with Bethesda VI cytology evaluated in a blinded fashion, the MTC Classifier was positive in two cases (1.80\%; Fig. 2). In clinical practice, Bethesda VI cases are not routinely tested with the GEC or MTC Classifier. Among Bethesda V cases, for which the treating physician requested MTC Classifier testing, six cases were positive, and all were confirmed to be MTC by either surgical pathology (five cases) or calcitonin in one case of a 73-year-old female with a serum calcitonin of $7721 \mathrm{ng} / \mathrm{L}$. This latter patient did not undergo thyroid surgery but had MRI findings suggestive of osseous metastases. Additionally, primary hyperparathyroidism suggested the possibility of multiple endocrine neoplasia (MEN) 2A (RET protooncogene mutation analysis not available). In all six cases, the cytology description suspected or diagnosed MTC. The five patients with surgically confirmed MTC had preoperative serum calcitonin values obtained $(M=1759 \mathrm{ng} / \mathrm{L}$; range $26-$ 5805 ng/L; Fig. 3).

In three Bethesda VI cases, the cytological description favored MTC, and the GEC was suspicious, but the MTC Classifier was negative. In two of the cases, preoperative serum calcitonin was undetectable, and PTC was found on surgical

Table 4. Independent Validation Set 3 (Current Study)

\begin{tabular}{|c|c|c|c|c|c|c|}
\hline & & Referenc & $d$ (truth) & & & ifier performance \\
\hline & & MTC+ & $M T C-$ & $\mathrm{N}$ & PPV & $97.7 \%(86.2-99.9 \%)$ \\
\hline Test & $\begin{array}{l}\text { MTC+ } \\
\text { MTC- }\end{array}$ & $\begin{array}{c}42 \\
\text { N/A }\end{array}$ & $\begin{array}{c}1 \\
\text { N/A }\end{array}$ & $\begin{array}{r}43 \\
10,445 \\
10,488\end{array}$ & & \\
\hline
\end{tabular}

Prospective, consecutively received, multicenter FNAB samples. Local or central cytopathology Bethesda III-VI, truth based on local histopathology (not masked to molecular results or serum calcitonin). As truth was not obtainable on all MTC test negative patients, only $\mathrm{PPV}$ is reported. 
Table 5. Pooled Analysis of All Three Independent Validation Sets

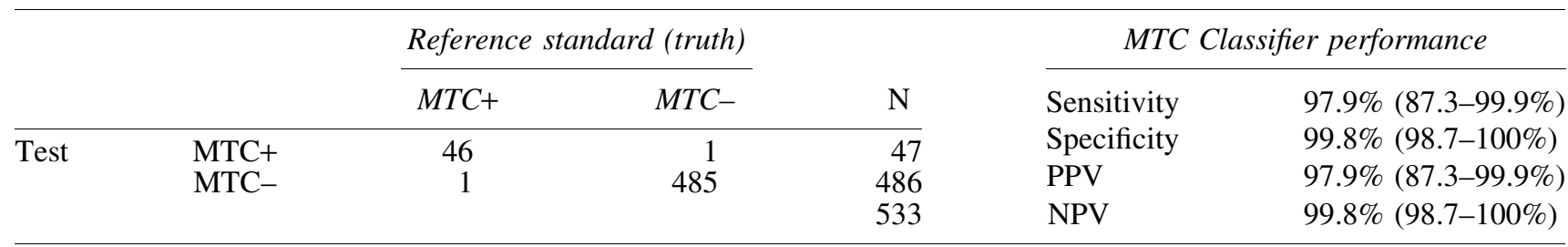

One false negative case described in this study included the pooled analysis.

histology. In the third case, the preoperative basal calcitonin was $4880 \mathrm{ng} / \mathrm{L}$, and surgical pathology demonstrated a $2 \mathrm{~cm}$ MTC; this case had the only false negative MTC Classifier result identified in this study of 10,488 tests.

\section{Baseline serum calcitonin}

Preoperative basal serum calcitonin values were available for 40 MTC patients identified by the MTC Classifier, including 37 with MTC confirmed on surgical pathology, while three were considered MTC based on a serum calcitonin $>80 \mathrm{ng} / \mathrm{L}$ without surgery (Supplementary Table S1; Supplementary Data are available online at www.liebertpub .com/thy). Two (5\%) surgically confirmed MTC cases had basal serum calcitonin values $<10 \mathrm{ng} / \mathrm{L}$, and three $(7.5 \%)$ were $<20 \mathrm{ng} / \mathrm{L}$, while eight of 40 cases $(20 \%)$ had calcitonin values $<100 \mathrm{ng} / \mathrm{L}$, a threshold above which most agree that surgery for suspected MTC is indicated (Fig. 3) $(6,23,33)$. The three MTCs with low basal serum calcitonin values $(<20 \mathrm{ng} / \mathrm{L})$ were all well-differentiated. Two were 1.0 and $1.3 \mathrm{~cm}$ in size and confined to the thyroid with calcitonin values of 5 and $18 \mathrm{ng} / \mathrm{L}$, respectively. The third was a $6 \mathrm{~mm}$ MTC with a metastatic lymph node and a calcitonin of $8 \mathrm{ng} / \mathrm{L}$. There were no obvious differences in basal serum calcitonin among MTC cases according to their Bethesda cytology category (Fig. 3). The authors are unaware of a similar published analysis.

\section{Multiple endocrine neoplasia type 2}

Among patients with surgically or biochemically confirmed MTC and Bethesda III/IV cytology, one of the 17 (5.9\%) RET

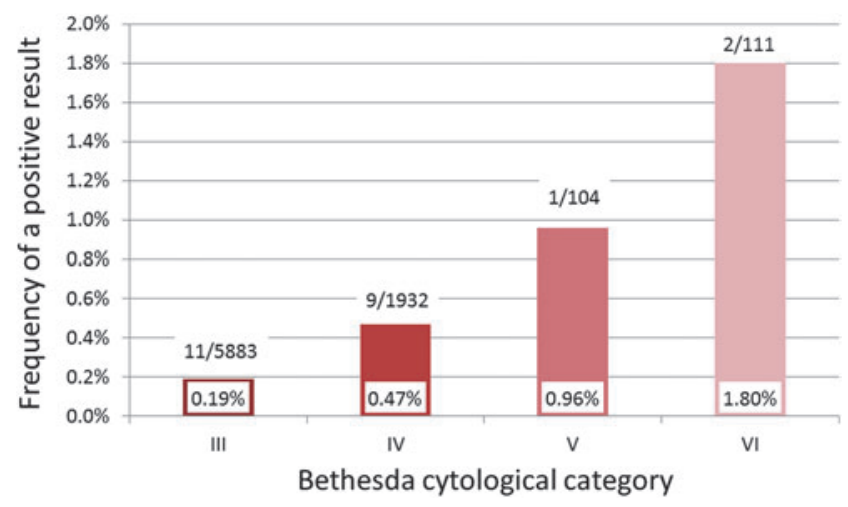

FIG. 2. Frequency of an mRNA expression signature suggestive of medullary thyroid carcinoma (MTC) among prospective consecutive nodules by Bethesda category. Values above the bars are those with positive MTC Classifier results over the total number of consecutively tested nodules in that Bethesda category. proto-oncogene tested patients was newly found to harbor a germline DNA mutation (Supplementary Table S1). Among tested Bethesda V/VI patients with positive MTC Classifier results, a germline RET mutation was present in $2 / 13$ (15.4\%).

\section{Discussion}

The limitation of thyroid FNAB cytopathology for the preoperative diagnosis of MTC has driven the search for alternative methods to diagnose MTC with greater efficacy $(6,11,16,23,27,28,34,37-45)$. Unfortunately, none have achieved international consensus for routine use. The most widely studied biomarker has been serum calcitonin, which demonstrates high diagnostic sensitivity but also a high false positive rate. Combined with the rarity of MTC, this results in a low PPV such that the majority of patients undergoing surgery due to high calcitonin levels do not have MTC on surgical pathology $(23,40)$. To limit false positives, one could limit calcitonin screening to those with cytologically indeterminate nodules rather than testing all patients with nodules (Fig. 4, Paradigm C), but these approaches would require a second patient visit (or serum sample storage pending the cytology result), and would not identify MTCs with serum

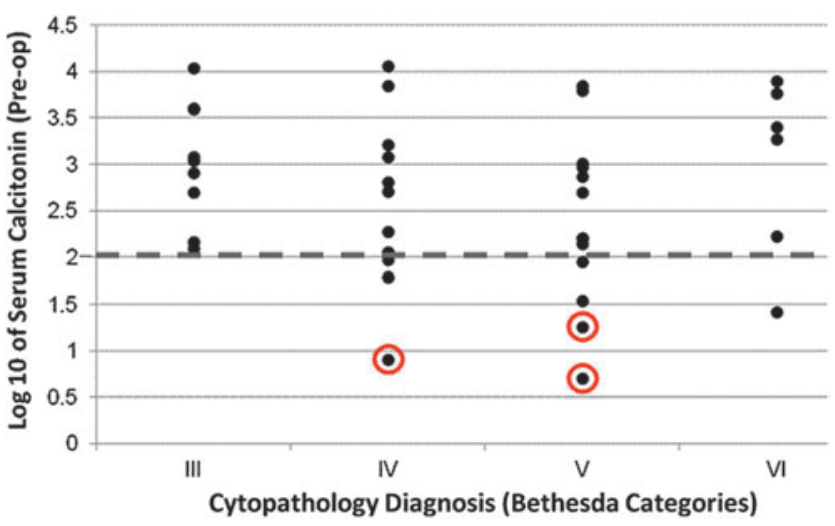

FIG. 3. Preoperative basal serum calcitonin values in 40 patients with MTC confirmed by surgical pathology (37 cases) or calcitonin $>80 \mathrm{ng} / \mathrm{L}$ without surgery. The dashed line at 2 on the $\log 10$ scale represents a serum calcitonin value of $100 \mathrm{ng} / \mathrm{L}$, a threshold above which most agree that surgery for suspected MTC is indicated $(6,23,33)$. Red circles encompass the three MTC with preoperative serum $\mathrm{Ct}$ $<20 \mathrm{ng} / \mathrm{L}$, a threshold commonly considered negative for MTC screening (16,34-36). Total patients by Bethesda category III-VI were $9,12,13$, and 6 , respectively. The upper reference range of serum calcitonin in adult women and men is approximately $5.2 \mathrm{ng} / \mathrm{L} \quad(\log 10=0.72)$ and $11.7 \mathrm{ng} / \mathrm{L}(\log 10=1.07)$, respectively $(31)$. 
FIG. 4. Three paradigms for cytologically indeterminate (Bethesda III/IV) nodules to test for MTC. Paradigm A utilizes the Afirma GEC and MTC Classifiers in a single test. Paradigm B utilizes the Afirma GEC Classifier but not the MTC Classifier, and then screens GEC suspicious patients with serum calcitonin. Paradigm $\mathrm{C}$ utilizes only serum calcitonin. The paradigms utilizing calcitonin assumed no benefit of stimulated calcitonin testing due to similar test performance or unavailability $(27,40,46)$. GEC, Gene Expression Classifier; ROM, risk of malignancy; PPV, positive predictive value. *Alexander et al. (47). "Frequency of a positive MTC Classifier in this series per Figure 2.

*Alexander et al. (24). ${ }^{\S} 1.15 \%$ prevalence of calcitonin $\geq 20 \mathrm{ng} / \mathrm{L}$ (16,34-36). ${ }^{\|} 81.8 \%$ operative rate for GEC suspicious nodules (47). "Operative rates of $64 \%$ and $72 \%$ for Bethesda III and IV, respectively (10). ${ }^{\#} 20$ positive MTC Classifier results (Fig. 2) and $7.5 \%$ of MTC cases have serum calcitonin $<20 \mathrm{ng} / \mathrm{L}$ in this series.

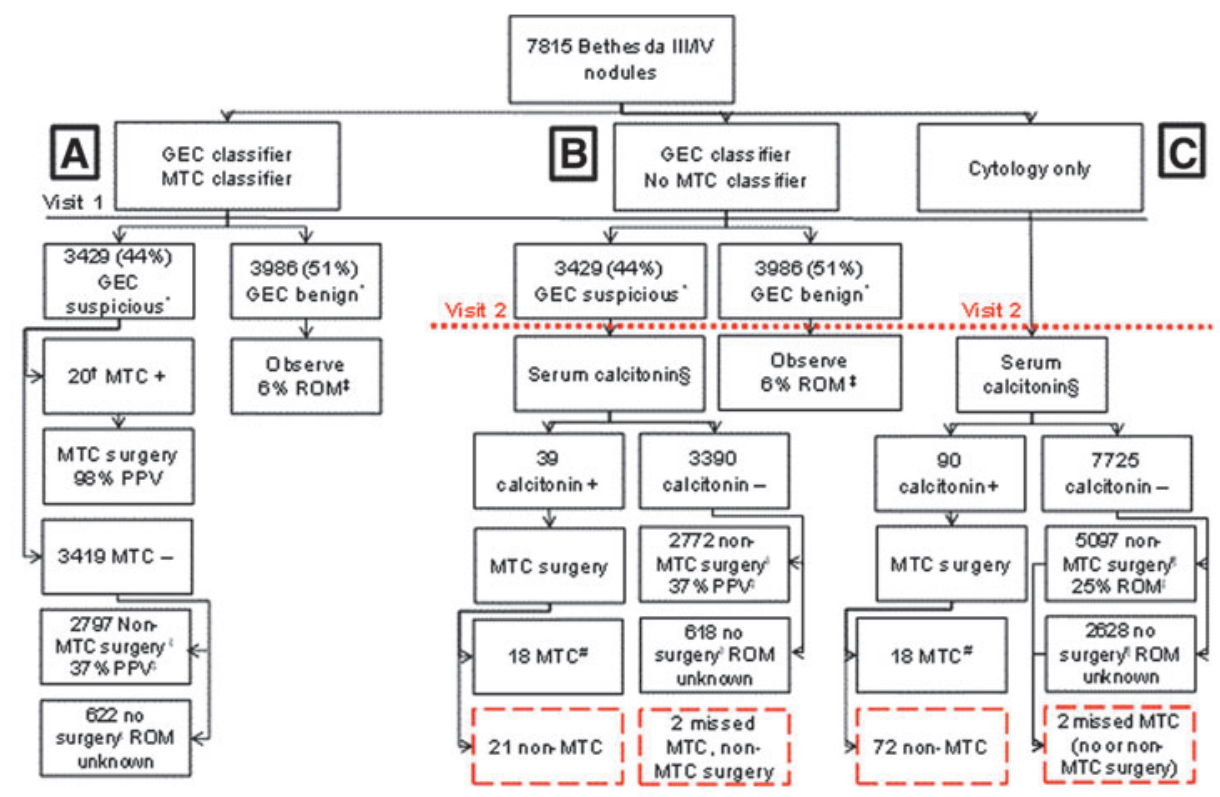

\begin{tabular}{|l|l|l|l|}
\hline Paradigm Summaries & PARADIGM A & PARADIGM B & PARADIGM C \\
\hline & $\begin{array}{l}\text { MTC Classifier } \\
\text { with GEC } \\
\text { Classifier }\end{array}$ & $\begin{array}{l}\text { GEC Classifier } \\
\text { with serum } \\
\text { calcitonin }\end{array}$ & $\begin{array}{l}\text { FNAB cytology } \\
\text { with serum } \\
\text { calcitonin }\end{array}$ \\
\hline MTCs detected/missed & $20 / 0$ & $18 / 2$ & $18 / 2$ \\
\hline $\begin{array}{l}\text { MTC-specific surgeries } \\
\text { N= } \\
\text { appropriate/inappropriate }\end{array}$ & $20 / 0$ & 39 & 90 \\
\hline $\begin{array}{l}\text { Non-MTC diagnostic } \\
\text { surgeries } \\
\text { N/PPV }\end{array}$ & $18 / 21$ & $18 / 72$ \\
\hline
\end{tabular}

calcitonin values below the chosen cutoff, which may occur in both differentiated and poorly differentiated tumors $(6,46,48)$. Most importantly, however, these approaches still result in an excess of false positive patients who undergo unnecessary preoperative MTC-specific evaluations and extensive MTC-specific surgery. Ironically, these false positive cases are more frequent than the actual number of true MTC cases found (Fig. 4, Paradigms B and C). While many advocate that an elevated baseline serum calcitonin should be followed by confirmatory stimulated serum calcitonin testing, the evidence that this improves diagnostic accuracy is not clear $(27,40,46)$, and the possibility of serious adverse effects (even if rare) needs to be considered (49). Further, pentagastrin, which is used for the measurement of stimulated calcitonin concentrations, is not available for human use in the United States, Canada, and some other countries (18). Because of the very low false positive rate and high sensitivity of the MTC Classifier, an alternative diagnostic algorithm is proposed where the MTC Classifier is used at the initial FNAB (Fig. 4, Paradigm A). This approach is costeffective when the GEC is already being used to reclassify cytologically indeterminate thyroid nodules as genomically suspicious or benign because the MTC Classifier result is automatically generated at the same time. Together, the GEC and the MTC Classifier provide actionable information on every patient tested. Almost all patients with Bethesda V/VI cytology undergo thyroid surgery without use of the GEC. For them, establishing the cost-effectiveness of preoperative MTC Classifier testing would require more formal investigation that considers the risks, benefits, costs (direct and indirect), complications of false positive and false negative results, alternative approaches such as serum or needle washout calcitonin measurement, and quality of life. Still, about one-quarter of MTC patients in these higher Bethesda categories would not be specifically identified as MTC by cytology (50). Yet, virtually all would be identified by the MTC Classifier.

High sensitivity, specificity, PPV, and NPV of the MTC Classifier were previously demonstrated in the prospectively collected, multicenter, and blinded validation study by Alexander et al. (Table 3) (24). That study was derived from a total enrollment of 4812 FNABs, of which 441 operated patients underwent GEC testing, including four histologically confirmed MTCs (Table 3). None of the 437 nodules with non-MTC histology were positive for the MTC Classifier, demonstrating exceptionally high specificity $(100 \%$ 
[CI 99-100\%]). All four MTCs were identified by the MTC Classifier (0, 2, and 2 MTCs among 61, 315, and 65 cytological Bethesda II, III-V, and VI categories, respectively), resulting in a perfect sensitivity (100\%). This large dataset yielded a high and narrow confidence interval of the NPV (98.9-100\%). That work has been extended by testing a large series of prospectively collected indeterminate FNABs to determine the prevalence of MTC positive results. To date, the current study represents the largest thyroid FNAB study evaluating the prevalence of MTC in routine clinical use. In this study, positive MTC Classifier results were found in each tested Bethesda category (III-VI), with the prevalence increasing in each successive category (Fig. 2). The prevalence of MTC among individual Bethesda categories III-VI has not been previously reported.

Out of 10,488 FNABs tested with the GEC, 43 cases tested positive by the MTC Classifier, with only one of these being a false positive, an intrathyroidal paraganglioma, an entity that is even rarer than MTC. As surgical resection is the standard treatment for paraganglioma, clinical utility of the MTC Classifier was not diminished. A plausible explanation for the positive MTC Classifier result is that both MTC and pheochromocytoma (intra-adrenal paraganglioma) are strongly positive for the granin family protein chromogranin A by immunohistochemistry (51). One of the MTC Classifier genes encodes another granin family protein, secretogranin III, present in association with chromogranin A in the secretory granules of neuroendocrine cells and known to show focal reactivity in pheochromocytomas (51). Of note, recently a post hoc analysis of a 15-gene subset of a 92-gene molecular classifier for tumor origin showed promise to distinguish pheochromocytoma and paraganglioma from MTC when using formalin-fixed, paraffin-embedded tissue samples and tumor enrichment (52). Feasibility or performance of this classifier on FNAB samples has not been reported.

Among the nine cases where cytopathology suggested MTC but the MTC Classifier was negative, only one of these cases proved to be MTC on surgical pathology, confirming a high NPV for this test. This is the only known false negative case among the 10,488 tested cases. In contrast to the high sensitivity of the MTC Classifier, cytology only suspected 19/ 43 cases (44\%) as MTC. This latter finding is consistent with the recent large international multicenter study where cytology made the specific diagnosis of MTC in $46 \%$ of cases (50).

Limitations of this study are that calcitonin, chromogranin, CEA, or thyroglobulin immunohistochemistry, or calcitonin levels in the needle washout in each case (53), were not studied. In routine practice, these would each add significant cost. Among cytologically indeterminate nodules, even if one of these methods excluded MTC, the possibility of a more common thyroid malignancy would remain. In contrast, the MTC Classifier result is generated concurrent with the GEC result at no added cost. The MTC Classifier sensitivity or NPV were also not computed on this cohort. To do so would require that all 10,445 MTC Classifier negative patients undergo surgical resection, despite the fact that many of them had genomically benign GEC results that likely allowed them to avoid diagnostic surgery - a clearly impractical study design. Despite this limitation, true and false positive cases were identified to compute the PPV for this cohort, given that "truth" (via surgical pathology in most, or serum calcitonin) was assigned to nearly all MTC Classifier positive cases. Only one false positive MTC Classifier result was identified among 7815 prospective consecutive cytologically Bethesda III/IV nodules tested with the Classifier $(0.013 \%)$. Specificity (true negatives/[true negatives + false positives]) is likely to be very high, given that only one false positive result was identified, and the rarity of MTC makes it highly likely that all (or nearly all) MTC Classifier negative cases are true negatives.

Clinical utility is established when a test improves the net health benefit for the patients and/or population in which it is used. Many believe that the benefit of screening for sporadic MTC with serum calcitonin has not been established because many of the tumors found are microcarcinomas with an unknown natural history (53). The MTC Classifier avoids this limitation by informing only on the specific nodule intentionally biopsied by the clinician. MTC is the only thyroid cancer where a total thyroidectomy and prophylactic central neck dissection is routinely recommended $(33,53)$. As half of MTC cases are not specifically identified by cytology alone $(5,6)$, a finding confirmed here, the preoperative identification of these malignancies by the MTC Classifier via a single test (Fig. 4) would allow an optimal initial surgical approach for MTC avoiding second "completion" surgeries, in addition to prompting the preoperative evaluation for MEN2.

Contrary to guideline recommendations, only 30/43 MTC patients identified in this series underwent RET protooncogene mutation testing $(33,53)$. This finding highlights a gap in clinical practice and suggests an opportunity for physician education. Of the 30 tested MTC patients, three (10\% [CI 3-28\%]) were found to harbor a germline RET mutation, which carries significant implications for the patient's family (Supplementary Table S1).

Here, the accuracy of MTC Classifier positive results is demonstrated among samples tested prospectively in routine, real-world clinical practice. The MTC Classifier identifies clinically relevant MTC in cytology specimens where MTC is often missed, allowing patients to receive the appropriate surgery at the first intervention, while simultaneously avoiding false positives that lead to unnecessary surgeries on patients without MTC. The MTC Classifier advances the ability to detect and correctly treat MTC earlier, and is an improvement over current methods.

\section{Acknowledgments}

The authors would like to thank the many physicians and healthcare professionals who provided information regarding patients in this study. We gratefully acknowledge Zhanzhi Hu, $\mathrm{PhD}$, and Mei Wong of Veracyte for assistance in establishing prevalence of MTC mRNA signatures among Bethesda cytology categories not routinely reflexed to the GEC.

\section{Author Disclosure Statement}

R.T.K., G.C.K., R.J.M., and R.B.L. are, or were, Veracyte employees. R.T.K., G.C.K., R.J.M., S.T.T., and R.B.L. are equity owners in Veracyte. GCK has U.S. Patent 8,541,170 issued. R.T.K. is a consultant to Novo Nordisk.

\section{References}

1. Aschebrook-Kilfoy B, Ward MH, Sabra MM, Devesa SS 2011 Thyroid cancer incidence patterns in the United States by histologic type, 1992-2006. Thyroid 21:125-134. 
2. Kebebew E, Ituarte PH, Siperstein AE, Duh QY, Clark OH 2000 Medullary thyroid carcinoma: clinical characteristics, treatment, prognostic factors, and a comparison of staging systems. Cancer 88:1139-1148.

3. Kebebew E, Greenspan FS, Clark OH, Woeber KA, Grunwell J 2005 Extent of disease and practice patterns for medullary thyroid cancer. J Am Coll Surg 200:890-896.

4. Roman S, Lin R, Sosa JA 2006 Prognosis of medullary thyroid carcinoma: demographic, clinical, and pathologic predictors of survival in 1252 cases. Cancer 107:2134-2142.

5. Trimboli P, Treglia G, Guidobaldi L, Romanelli F, Nigri G, Valabrega S, Sadeghi R, Crescenzi A, Faquin WC, Bongiovanni M, Giovanella L 2015 Detection rate of FNA cytology in medullary thyroid carcinoma: a meta-analysis. Clin Endocrinol (Oxf). 82:280-285.

6. Ha EJ, Baek JH, Na DG, Kim JH, Kim JK, Min HS, Song DE, Lee KE, Shong YK 2015 The role of core needle biopsy and its impact on surgical management in patients with medullary thyroid cancer: clinical experience at 3 medical institutions. AJNR Am J Neuroradiol 36:1512-1517.

7. Esfandiari NH, Hughes DT, Yin H, Banerjee M, Haymart MR 2014 The effect of extent of surgery and number of lymph node metastases on overall survival in patients with medullary thyroid cancer. J Clin Endocrinol Metab 99:448-454.

8. Panigrahi B, Roman SA, Sosa JA 2010 Medullary thyroid cancer: are practice patterns in the United States discordant from American Thyroid Association guidelines? Ann Surg Oncol 17:1490-1498.

9. Verbeek HH, Meijer JA, Zandee WT, Kramp KH, Sluiter WJ, Smit JW, Kievit J, Links TP, Plukker JT 2015 Fewer cancer reoperations for medullary thyroid cancer after initial surgery according to ATA guidelines. Ann Surg Oncol 22:1207-1213.

10. Cibas ES, Baloch ZW, Fellegara G, LiVolsi VA, Raab SS, Rosai J, Diggans J, Friedman L, Kennedy GC, Kloos RT, Lanman RB, Mandel SJ, Sindy N, Steward DL, Zeiger MA, Haugen BR, Alexander EK 2013 A prospective assessment defining the limitations of thyroid nodule pathologic evaluation. Ann Intern Med 159:325-332.

11. Shah SS, Faquin WC, Izquierdo R, Khurana KK 2009 FNA of misclassified primary malignant neoplasms of the thyroid: Impact on clinical management. Cytojournal 6:1.

12. Jo VY, Stelow EB, Dustin SM, Hanley KZ 2010 Malignancy risk for fine-needle aspiration of thyroid lesions according to the Bethesda System for Reporting Thyroid Cytopathology. Am J Clin Pathol 134:450-456.

13. Fischer AH, Clayton AC, Bentz JS, Wasserman PG, Henry MR, Souers RJ, Moriarty AT 2013 Performance differences between conventional smears and liquid-based preparations of thyroid fine-needle aspiration samples: analysis of 47,076 responses in the College of American Pathologists Interlaboratory Comparison Program in Non-Gynecologic Cytology. Arch Pathol Lab Med 137:26-31.

14. Moura MM, Cavaco BM, Leite V 2015 RAS protooncogene in medullary thyroid carcinoma. Endocr Relat Cancer 22:R235-252.

15. Pagan M, Kloos RT, Lin CF, Travers KJ, Matsuzaki H, Tom EY, Kim SY, Wong MG, Stewart AC, Huang J, Walsh PS, Monroe RJ, Kennedy GC 2016 The diagnostic application of RNA sequencing in patients with thyroid cancer: an analysis of 851 variants and 133 fusions in 524 genes. BMC Bioinformatics 17:6.

16. Costante G, Meringolo D, Durante C, Bianchi D, Nocera M, Tumino S, Crocetti U, Attard M, Maranghi M, Tor- lontano M, Filetti S 2007 Predictive value of serum calcitonin levels for preoperative diagnosis of medullary thyroid carcinoma in a cohort of 5817 consecutive patients with thyroid nodules. J Clin Endocrinol Metab 92:450-455.

17. Pusztaszeri MP, Bongiovanni M, Faquin WC 2014 Update on the cytologic and molecular features of medullary thyroid carcinoma. Adv Anat Pathol 21:26-35.

18. Haugen BR, Alexander EK, Bible KC, Doherty GM, Mandel SJ, Nikiforov YE, Pacini F, Randolph GW, Sawka AM, Schlumberger M, Schuff KG, Sherman SI, Sosa JA, Steward DL, Tuttle RM, Wartofsky L 20162015 American Thyroid Association Management Guidelines for Adult Patients with Thyroid Nodules and Differentiated Thyroid Cancer: The American Thyroid Association Guidelines Task Force on Thyroid Nodules and Differentiated Thyroid Cancer. Thyroid 26:1-133.

19. NCCN Clinical Practice Guidelines in Oncology. Thyroid Carcinoma. Available at: www.nccn.org/professionals/ physician_gls/pdf/thyroid.pdf (accessed January 27, 2016).

20. Ross DS 2015 Diagnostic approach to and treatment of thyroid nodules. In: Cooper DS, Mulder JE (eds) UpToDate. UpToDate, Waltham, MA.

21. Rosario PW, Ward LS, Carvalho GA, Graf H, Maciel RM, Maciel LM, Maia AL, Vaisman M 2013 Thyroid nodules and differentiated thyroid cancer: update on the Brazilian consensus. Arq Bras Endocrinol Metabol 57:240-264.

22. Perros P, Boelaert K, Colley S, Evans C, Evans RM, Gerrard Ba G, Gilbert J, Harrison B, Johnson SJ, Giles TE, Moss L, Lewington V, Newbold K, Taylor J, Thakker RV, Watkinson J, Williams GR 2014 Guidelines for the management of thyroid cancer. Clin Endocrinol (Oxf) 81:1-122.

23. Costante G, Durante C, Francis Z, Schlumberger M, Filetti S 2009 Determination of calcitonin levels in C-cell disease: clinical interest and potential pitfalls. Nat Clin Pract Endocrinol Metab 5:35-44.

24. Alexander EK, Kennedy GC, Baloch ZW, Cibas ES, Chudova D, Diggans J, Friedman L, Kloos RT, LiVolsi VA, Mandel SJ, Raab SS, Rosai J, Steward DL, Walsh PS, Wilde JI, Zeiger MA, Lanman RB, Haugen BR 2012 Preoperative diagnosis of benign thyroid nodules with indeterminate cytology. N Engl J Med 367:705-715.

25. Chudova D, Wilde JI, Wang ET, Wang H, Rabbee N, Egidio CM, Reynolds J, Tom E, Pagan M, Rigl CT, Friedman L, Wang CC, Lanman RB, Zeiger M, Kebebew E, Rosai J, Fellegara G, LiVolsi VA, Kennedy GC 2010 Molecular classification of thyroid nodules using high-dimensionality genomic data. J Clin Endocrinol Metab 95:5296-5304.

26. Cibas ES, Ali SZ 2009 The Bethesda System for Reporting Thyroid Cytopathology. Thyroid 19:1159-1165.

27. Colombo C, Verga U, Mian C, Ferrero S, Perrino M, Vicentini L, Dazzi D, Opocher G, Pelizzo MR, BeckPeccoz P, Fugazzola L 2012 Comparison of calcium and pentagastrin tests for the diagnosis and follow-up of medullary thyroid cancer. J Clin Endocrinol Metab 97:905-913.

28. Ahmed SR, Ball DW 2011 Clinical review: incidentally discovered medullary thyroid cancer: diagnostic strategies and treatment. J Clin Endocrinol Metab 96:1237-1245.

29. Machens A, Hoffmann F, Sekulla C, Dralle H 2009 Importance of gender-specific calcitonin thresholds in screening for occult sporadic medullary thyroid cancer. Endocr Relat Cancer 16:1291-1298.

30. Pankratz D, Hu Z, Kim SY, Monroe R, Wong M, Diggans J, Traweek T, Kumm J, Lanman R, Kloos R, Walsh S, Kennedy G 2014 Analytical validation of a gene expression classifier for medullary thyroid carcinoma (abstract) 
American Association of Clinical Endocrinologists Annual Meeting, Las Vegas, NV.

31. Basuyau JP, Mallet E, Leroy M, Brunelle P 2004 Reference intervals for serum calcitonin in men, women, and children. Clin Chem 50:1828-1830.

32. Newcombe RG 1998 Two-sided confidence intervals for the single proportion: comparison of seven methods. Stat Med 17:857-872.

33. American Thyroid Association Guidelines Task F, Kloos RT, Eng C, Evans DB, Francis GL, Gagel RF, Gharib H, Moley JF, Pacini F, Ringel MD, Schlumberger M, Wells SA Jr 2009 Medullary thyroid cancer: management guidelines of the American Thyroid Association. Thyroid 19:565-612.

34. Elisei R, Bottici V, Luchetti F, Di Coscio G, Romei C, Grasso L, Miccoli P, Iacconi P, Basolo F, Pinchera A, Pacini F 2004 Impact of routine measurement of serum calcitonin on the diagnosis and outcome of medullary thyroid cancer: experience in 10,864 patients with nodular thyroid disorders. J Clin Endocrinol Metab 89:163-168.

35. Hegedus L, Moses AC, Zdravkovic M, Le Thi T, Daniels GH 2011 GLP-1 and calcitonin concentration in humans: lack of evidence of calcitonin release from sequential screening in over 5000 subjects with type 2 diabetes or nondiabetic obese subjects treated with the human GLP-1 analog, liraglutide. J Clin Endocrinol Metab 96:853-860.

36. Daniels GH, Hegedus L, Marso SP, Nauck MA, Zinman B, Bergenstal RM, Mann JF, Karsbol JD, Moses AC, Buse JB, Tuttle RM 2015 LEADER 2: baseline calcitonin in 9340 people with Type 2 diabetes enrolled in the Liraglutide Effect and Action in Diabetes: Evaluation of cardiovascular outcome Results (LEADER) Trial: preliminary observations. Diabetes Obes Metab 17:477-486.

37. Trimboli P, Nigri G, Romanelli F, Cicciarella Modica DD, Crescenzi A, Valabrega S, Giovanella L 2012 Medullary thyroid nodules by measurement of calcitonin $(\mathrm{Ct})$ in aspiration needle washout in patients with multinodular goiter and moderately elevated serum Ct. Exp Clin Endocrinol Diabetes 120:234-237.

38. Diazzi C, Madeo B, Taliani E, Zirilli L, Romano S, Granata AR, De Santis MC, Simoni M, Cioni K, Carani C, Rochira V 2013 The diagnostic value of calcitonin measurement in wash-out fluid from fine-needle aspiration of thyroid nodules in the diagnosis of medullary thyroid cancer. Endocr Pract 19:769-779.

39. Forrest CH, Frost FA, de Boer WB, Spagnolo DV, Whitaker D, Sterrett BF 1998 Medullary carcinoma of the thyroid: accuracy of diagnosis of fine-needle aspiration cytology. Cancer 84:295-302.

40. Rink T, Truong PN, Schroth HJ, Diener J, Zimny M, Grunwald F 2009 Calculation and validation of a plasma calcitonin limit for early detection of medullary thyroid carcinoma in nodular thyroid disease. Thyroid 19:327-332.

41. Boi F, Maurelli I, Pinna G, Atzeni F, Piga M, Lai ML, Mariotti S 2007 Calcitonin measurement in wash-out fluid from fine needle aspiration of neck masses in patients with primary and metastatic medullary thyroid carcinoma. J Clin Endocrinol Metab 92:2115-2118.

42. Bugalho MJ, Mendonca E, Sobrinho LG 2000 Medullary thyroid carcinoma: an accurate pre-operative diagnosis by reverse transcription-PCR. Eur J Endocrinol 143:335-338.

43. Giovanella L, Verburg FA, Imperiali M, Valabrega S, Trimboli P, Ceriani L 2013 Comparison of serum calcitonin and procalcitonin in detecting medullary thyroid carcinoma among patients with thyroid nodules. Clin Chem Lab Med 51:1477-1481.

44. Camacho CP, Lindsey SC, Melo MC, Yang JH, GermanoNeto F, Valente Fde O, Lima TR, Biscolla RP, Vieira JG, Cerutti JM, Dias-da-Silva MR, Maciel RM 2013 Measurement of calcitonin and calcitonin gene-related peptide mRNA refines the management of patients with medullary thyroid cancer and may replace calcitonin-stimulation tests. Thyroid 23:308-316.

45. Trimboli P, Seregni E, Treglia G, Alevizaki M, Giovanella L 2015 Procalcitonin for detecting medullary thyroid carcinoma: a systematic review. Endocr Relat Cancer 22:R157-164.

46. Mian C, Perrino M, Colombo C, Cavedon E, Pennelli G, Ferrero S, De Leo S, Sarais C, Cacciatore C, Manfredi GI, Verga U, Iacobone M, De Pasquale L, Pelizzo MR, Vicentini L, Persani L, Fugazzola L 2014 Refining calcium test for the diagnosis of medullary thyroid cancer: cutoffs, procedures, and safety. J Clin Endocrinol Metab 99:1656-1664.

47. Alexander EK, Schorr M, Klopper J, Kim C, Sipos J, Nabhan F, Parker C, Steward DL, Mandel SJ, Haugen BR 2014 Multicenter clinical experience with the Afirma gene expression classifier. J Clin Endocrinol Metab 99:119-125.

48. Frank-Raue K, Machens A, Leidig-Bruckner G, Rondot S, Haag C, Schulze E, Lorenz A, Kreissl MC, Dralle H, Raue F, Schmid KW 2013 Prevalence and clinical spectrum of nonsecretory medullary thyroid carcinoma in a series of 839 patients with sporadic medullary thyroid carcinoma. Thyroid 23:294-300.

49. Russo M, Scollo C, Padova G, Vigneri R, Pellegriti G 2014 Cardiac arrest after intravenous calcium administration for calcitonin stimulation test. Thyroid 24:606-607.

50. Essig GF Jr, Porter K, Schneider D, Debora A, Lindsey SC, Busonero G, Fineberg D, Fruci B, Boelaert K, Smit JW, Meijer JA, Duntas L, Sharma N, Costante G, Filetti S, Sippel RS, Biondi B, Topliss DJ, Pacini F, Maciel RM, Walz PC, Kloos RT 2013 Fine needle aspiration and medullary thyroid carcinoma: the risk of inadequate preoperative evaluation and initial surgery when relying upon FNAB cytology alone. Endocr Pract 19:920-927.

51. Portela-Gomes GM, Grimelius L, Stridsberg M 2010 Secretogranin III in human neuroendocrine tumours: a comparative immunohistochemical study with chromogranins A and B and secretogranin II. Regul Pept 165:30-35.

52. Kerr SE, Schnabel CA, Sullivan PS, Zhang Y, Huang VJ, Erlander MG, Brachtel EF, Dry SM 2014 A 92-gene cancer classifier predicts the site of origin for neuroendocrine tumors. Mod Pathol 27:44-54.

53. Wells SA Jr, Asa SL, Dralle H, Elisei R, Evans DB, Gagel RF, Lee N, Machens A, Moley JF, Pacini F, Raue F, FrankRaue K, Robinson B, Rosenthal MS, Santoro M, Schlumberger M, Shah M, Waguespack SG, American Thyroid Association Guidelines Task Force on Medullary Thyroid Cancer 2015 Revised American Thyroid Association guidelines for the management of medullary thyroid carcinoma. Thyroid 25:567-610.

Address correspondence to: Richard T. Kloos, MD Department of Medical Affairs Veracyte, Inc. 6000 Shoreline Court South San Francisco, CA 94080

E-mail: Richard.Kloos@Veracyte.com 